\title{
Results of a Medication Reconciliation Survey from the 2006 Society of Hospital Medicine National Meeting
}

\author{
Brian J. Clay, mo ${ }^{1}$ \\ Lakshmi Halasyamani, MD $^{2}$ \\ Erin R. Stucky, MD $^{3}$ \\ Jeffrey L. Greenwald, $\mathrm{MD}^{4}$ \\ Mark V. Williams, MD $^{5}$ \\ ${ }^{1}$ Assistant Professor of Medicine, Division of \\ Hospital Medicine, University of California San \\ Diego, California. \\ ${ }^{2}$ Vice Chair, Department of Internal Medicine, \\ Saint Joseph Mercy Hospital, Ann Arbor, \\ Michigan. \\ ${ }^{3}$ Clinical Professor of Pediatrics, University of \\ California San Diego; Pediatric Hospital Medicine \\ Fellowship Director, Rady Children's Hospital San \\ Diego, California. \\ ${ }^{4}$ Director, Hospital Medicine Unit, Boston Medical \\ Center; Associate Professor of Medicine, Boston \\ University School of Medicine, Boston, Massa- \\ chusetts. \\ ${ }^{5}$ Chief, Division of Hospital Medicine, Northwes- \\ tern University Feinberg School of Medicine, \\ Chicago, Illinois.
}

BACKGROUND: The status of implementation of medication reconciliation across hospitals is variable to date; the degree to which hospitalists are involved is not known. METHODS: To better describe the current state of medication reconciliation implementation, we conducted a survey of attendees of the 2006 Society of Hospital Medicine national meeting.

RESULTS: We identified a lack of uniformity across hospitals with respect to the degree of process implementation. Hospitalists were involved in design and implementation in a majority of cases, and felt that medication reconciliation would likely have a positive impact on patient safety. Tertiary care academic centers were more likely to use physicians to perform medication reconciliation, whereas community hospitals were more likely to involve nurses as well. Pharmacist participation in the medication reconciliation process was found to be quite low. Process and outcome measures were used infrequently. Patients' lack of medication knowledge and absence of preadmission medication information were cited most frequently as barriers to implementation of medication reconciliation.

CONCLUSIONS: Implementation of medication reconciliation is complex and challenging. Medication information is often incomplete, and elements of the medication reconciliation process result in increased time demands on providers. Current implementation efforts often have physicians and nurses "share" responsibility for compliance, and pharmacists are underutilized in medication reconciliation processes. Hospitalists have thus far played a substantial role in process design and implementation, and should continue to lead the way in advancing efforts to successfully implement medication reconciliation. Journal of Hospital Medicine 2008;3(6):465-472. (ㅇ 2008 Society of Hospital Medicine.

KEYWORDS: medication reconciliation, patient safety, quality control, Society of Hospital Medicine.

$\mathbf{T}$ he Joint Commission's (TJC) National Patient Safety Goal (NPSG) \#8- "Accurately and completely reconcile medications across the continuum of care"-challenges hospitals to design and implement new medication management processes. With medication errors contributing to patient morbidity and mortality, ${ }^{1}$ establishing a comprehensive process for reconciling a patient's medications during the hospitalization episode is an important quality improvement and patient safety goal.

However, the current state of inpatient medication management is highly fragmented. Standard documentation is lacking, as is integration of information between care settings. ${ }^{2}$ There are now reports describing implementation of various medication reconciliation processes for admissions, ${ }^{3}$ transfers, ${ }^{4}$ and discharges. ${ }^{5}$ 
Hospitalists are well-positioned to contribute to the implementation of medication reconciliation. Indeed, because TJC does not explicitly specify what type of health care provider (eg, physician, nurse, etc.) should assume responsibility for this process, institutions have designed workflows to suit their own needs, while striving to comply with national standards.

Given the complexity and lack of standardization around this NPSG, a survey was distributed to attendees of a Society of Hospital Medicine (SHM) national meeting to determine the various processes implemented thus far, and to ascertain existing challenges to implementation. We report here on the results.

\section{METHODS}

A survey tool (Appendix) was designed to query demographic and institutional factors, involvement in the process, and barriers to implementation of medication reconciliation. Surveys were included in all attendees' registration materials, resulting in the distributions of approximately 800 surveys.

Responses were entered into an Excel spreadsheet. Simple descriptive statistics were used to determine proportions for providers, processes, and barriers to implementation. Where appropriate, variables were dichotomized, allowing for paired $t$-test analysis. Statistical significance was defined as a $P$ value less than .05 . Subgroup analyses by hospital type, provider type, and process method were performed.

\section{RESULTS}

A total of 295 completed surveys were collected. The responses are tabulated in Table 1.

\section{Process}

A paper process was used most often (47\%), followed by a combined process $(31 \%)$, and computers alone in just $11 \%$ of cases. Measurement of process compliance was reported in less than half (42\%), with $34 \%$ unaware if their institutions were monitoring compliance. Outcome measurement was recorded as "not performed" (25\%) or "unknown" (41\%) in a majority of cases. Respondents reported a favorable view of the future impact of medication reconciliation, with $58 \%$ citing likely positive impacts on patient safety and patient care; fewer were unsure (14\%) or anticipated no impact $(9 \%)$ or negative impact $(7 \%)$. Survey results regard-
TABLE 1

Survey Responses

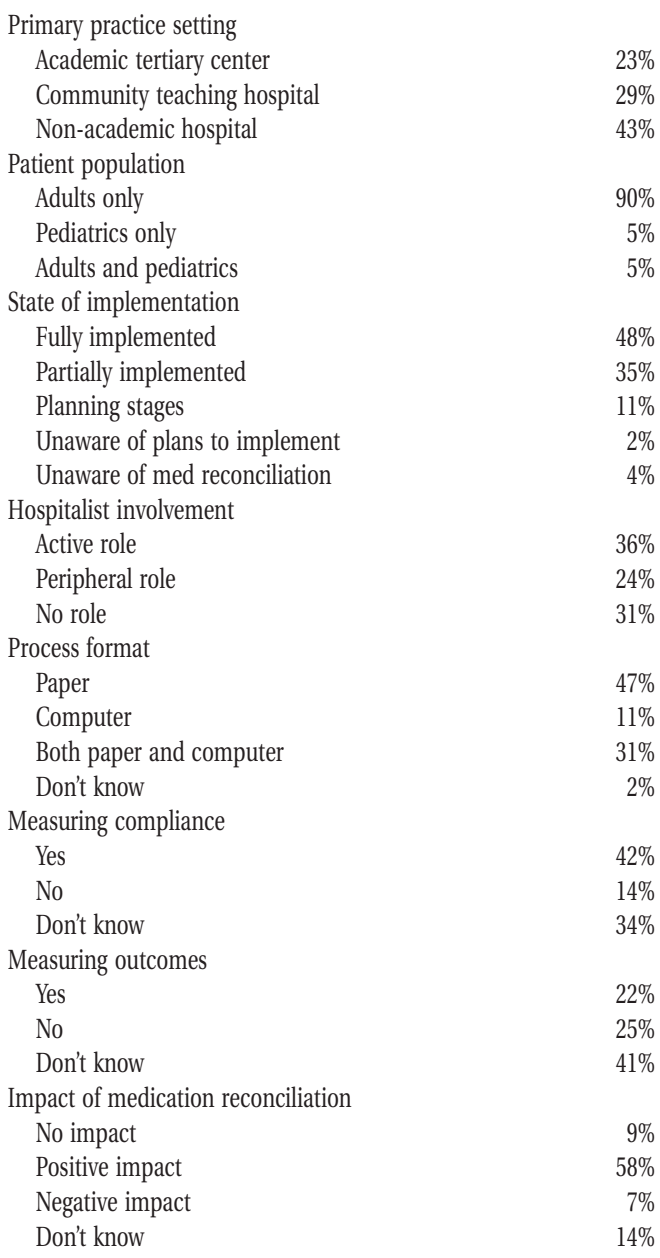

Response totals may not always total $100 \%$ due to some answers being left blank. Percentages reported are of the total of 295 surveys.

ing responsibility for individual process steps are detailed in Table 2. Notably, respondents often indicated that both physicians and nurses would share responsibility for a given step. Physicians were more often responsible for reconciling home medications, updating discharge medication lists, and communicating to outpatient providers. Nursing performed reconciliation in only $10 \%$ of cases. Results across all steps demonstrated very low participation rates by pharmacists, with pharmacist responsibility for reconciliation only $6 \%$ of the time.

\section{Hospital Type}

Results of subgroup analyses by hospital type are detailed in Table 3. Community teaching hospitals 
TABLE 2

Survey Responses - Medication Reconciliation Process Steps

\begin{tabular}{|c|c|c|c|c|c|}
\hline Process Step & Physician & Nurse & Physician and Nurse & Pharmacist & Other \\
\hline Obtaining home med list & $15 \%$ & $39 \%$ & $41 \%$ & $3 \%$ & $2 \%$ \\
\hline Documenting home med list & $17 \%$ & $41 \%$ & $37 \%$ & $2 \%$ & $3 \%$ \\
\hline Reconciling medications & $56 \%$ & $10 \%$ & $21 \%$ & $6 \%$ & $7 \%$ \\
\hline Updating discharge med list & $64 \%$ & $6 \%$ & $17 \%$ & $3 \%$ & $10 \%$ \\
\hline Providing instructions at discharge & $15 \%$ & $46 \%$ & $32 \%$ & $2 \%$ & $5 \%$ \\
\hline Communicating changes at follow-up & $84 \%$ & $6 \%$ & $4 \%$ & $6 \%$ & $1 \%$ \\
\hline
\end{tabular}

Response totals may not always total $100 \%$ due to some answers being left blank. Percentages reported are of the total of 295 surveys.

(CTHs) were significantly more likely (57\%) than nonteaching hospitals (NTHs) (49\%) or tertiary academic centers (TACs) (35\%) to have achieved full implementation. NTHs were significantly less likely to have involved hospitalists in implementation. Use of computer-based processes at TACs was more common $(27 \%)$ than in CTHs $(9 \%)$ or NTHs (7\%). TACs were significantly more likely to have a physician obtain the medication list $(33 \%$, compared with $15 \%$ and $7 \%$ for CTHs and NTHs, respectively), whereas NTHs were more likely to use nurses $(50 \%)$ than were CTHs $(31 \%)$ or TACs $(26 \%)$. Similar significant differences were found among hospital types with regard to obtaining the preadmission medication list. Physicians in TACs (25\%) were more likely to be responsible for giving discharge medication instructions than in CTHs (10\%) or NTHs (14\%, not significant compared with TACs).

\section{Barriers}

Results regarding barriers to successful implementation are shown in Table 4. Patient lack of knowledge of medications (87\%) and absence of a preadmission medication list from other sources (80\%) were common. Both paper and computer medication reconciliation processes were associated with respondents citing cumbersome hospital systems as a barrier; this barrier was cited more often when the implemented process was paperonly (Table 5). Respondents who stated the medication reconciliation process takes too long did so regardless of whether the implemented process was paper-based or computer-based. Despite these barriers, only $16 \%$ of respondents stated that medication reconciliation was not worth the effort of implementation. Barriers reported were similar across hospital type (Table 6) with 2 exceptions. Formulary differences were noted to be a barrier more often in CTHs (78\%) compared with NTHs (60\%) and TACs (64\%, not significant compared with CTHs). Language barriers were problematic more often in TACs $(48 \%)$ than in NTHs $(28 \%)$ or CTHs (36\%, not significant compared with TACs).

\section{DISCUSSION}

Managing medication information for inpatients is an extremely complex task. On admission, home medication lists are often inaccurate or absent, ${ }^{6}$ requiring extra time and effort to discover this information. By discharge, medication regimens have frequently been altered, ${ }^{7}$ making communication of changes to the next provider essential. One study described myriad provider, patient, and health system issues in maintaining accurate outpatient medication lists. ${ }^{8}$ These issues are further compounded by the multiple prescribers, necessary hand-offs, and formulary differences in the inpatient setting.

Over half of the hospitalists in this survey reported hospitalist involvement in design and implementation of medication reconciliation. Given the familiarity with hospital systems and inpatient workflow, hospitalists are well-positioned to contribute to successful implementation. Nonetheless, many were unaware of efforts to implement this NPSG.

Measurement of both process and outcome measures is important when determining value in quality improvement. Beyond process measures, outcome measures such as adverse drug events, readmission rates, mortality, patient satisfaction, and outpatient provider satisfaction may be appropriate in evaluating medication reconciliation strategies. Even measuring the accuracy of the process with respect to the admission orders written would be a valuable source of information for further improvement. Unfortunately, respondents indicated that evaluation was occurring infrequently. Potentially more problematic is the apparent lack of 
TABLE 3

Subgroup Analysis by Hospital Type

\begin{tabular}{|c|c|c|c|c|c|c|}
\hline & \multirow{2}{*}{$\begin{array}{l}\text { Academic } \\
\text { Centers }[\mathrm{AC}]\end{array}$} & \multirow{2}{*}{$\begin{array}{l}\text { Community } \\
\text { Teaching } \\
\text { Hospitals [CT] }\end{array}$} & \multirow{2}{*}{$\begin{array}{l}\text { Non-Teaching } \\
\text { Hospitals [NT] }\end{array}$} & \multicolumn{3}{|c|}{$P$ values (2-tailed) } \\
\hline & & & & $\mathrm{AC}$ vs. $\mathrm{CT}$ & $\mathrm{AC}$ vs. NT & CT vs. NT \\
\hline \multicolumn{7}{|l|}{ State of implementation } \\
\hline Fully implemented & 25/71 (35) & 48/84 (57) & 68/139 (49) & 0.007 & 0.06 & 0.25 \\
\hline Partially implemented & 31/71 (44) & 25/84 (30) & 48/139 (35) & 0.07 & 0.21 & 0.44 \\
\hline Planning stages & 9/71 (13) & 9/84 (11) & $14 / 139(10)$ & 0.70 & 0.51 & 0.81 \\
\hline Unaware of plans to implement & 2/71 (3) & $1 / 84(1)$ & $3 / 139(2)$ & 0.37 & 0.65 & 0.57 \\
\hline Unaware of med reconciliation & $4 / 71(5)$ & $1 / 84(1)$ & $6 / 139(4)$ & 0.14 & 0.74 & 0.19 \\
\hline \multicolumn{7}{|l|}{ Hospitalist involvement } \\
\hline Active role & $28 / 59(47)$ & $34 / 80(43)$ & 43/127 (34) & 0.64 & 0.09 & 0.19 \\
\hline Peripheral role & $12 / 59(20)$ & $25 / 80(31)$ & $34 / 127$ (27) & 0.15 & 0.30 & 0.54 \\
\hline No role & 19/59 (32) & $19 / 80(24)$ & $50 / 127(39)$ & 0.30 & 0.36 & 0.03 \\
\hline \multicolumn{7}{|l|}{ Process format } \\
\hline Paper & $26 / 59(44)$ & $47 / 81(58)$ & $63 / 127(50)$ & 0.10 & 0.45 & 0.26 \\
\hline Computer & $16 / 59(27)$ & 7/81 (9) & 9/127 (7) & 0.005 & $<0.001$ & 0.60 \\
\hline Both paper and computer & $17 / 59(29)$ & 25/81 (31) & $51 / 127(40)$ & 0.80 & 0.15 & 0.19 \\
\hline Don't know & $0 / 59(0)$ & $2 / 81(2)$ & 4/127 (3) & 0.28 & 0.18 & 0.66 \\
\hline \multicolumn{7}{|l|}{ Process steps (selected questions) } \\
\hline \multicolumn{7}{|l|}{ Obtaining home med list } \\
\hline Physician & 19/58 (33) & $12 / 80(15)$ & $9 / 125(7)$ & 0.013 & $<0.001$ & 0.07 \\
\hline Physician and Nurse & 19/58 (33) & $39 / 80(49)$ & 49/125 (39) & 0.47 & 0.44 & 0.16 \\
\hline Nurse & $15 / 58(26)$ & $25 / 80(31)$ & $62 / 125(50)$ & 0.005 & 0.003 & 0.008 \\
\hline Pharmacist & $5 / 58(9)$ & 1/80 (1) & 2/125 (2) & 0.06 & 0.03 & 0.58 \\
\hline \multicolumn{7}{|l|}{ Documenting home med list } \\
\hline Physician & $22 / 58(38)$ & $11 / 80(14)$ & $11 / 125(9)$ & 0.001 & $<0.001$ & 0.26 \\
\hline Physician and Nurse & $15 / 58(26)$ & $37 / 80(46)$ & $45 / 125(36)$ & 0.02 & 0.18 & 0.16 \\
\hline Nurse & $18 / 58(31)$ & $26 / 80(32)$ & $64 / 125(51)$ & 0.90 & 0.012 & 0.008 \\
\hline Pharmacist & $3 / 58(5)$ & $2 / 80(3)$ & $1 / 125(1)$ & 0.55 & 0.09 & 0.29 \\
\hline \multicolumn{7}{|l|}{ Reconciling medications } \\
\hline Physician & $33 / 58(57)$ & $51 / 80(64)$ & $63 / 125(50)$ & 0.41 & 0.42 & 0.051 \\
\hline Physician and Nurse & 8/58 (14) & $14 / 80(18)$ & $32 / 125(26)$ & 0.53 & 0.09 & 0.18 \\
\hline Nurse & 6/58 (10) & $6 / 80(8)$ & $15 / 125(12)$ & 0.68 & 0.71 & 0.36 \\
\hline Pharmacist & 8/58 (14) & $5 / 80(6)$ & 3/125 (2) & 0.11 & 0.007 & 0.13 \\
\hline \multicolumn{7}{|l|}{ Updating discharge med list } \\
\hline Physician & $42 / 58(72)$ & $50 / 80(63)$ & $76 / 125(61)$ & 0.27 & 0.15 & 0.77 \\
\hline Physician and Nurse & 7/58 (12) & $16 / 80(20)$ & 23/125 (18) & 0.22 & 0.31 & 0.72 \\
\hline Nurse & $2 / 58(3)$ & $5 / 80(6)$ & $10 / 125(8)$ & 0.41 & 0.20 & 0.59 \\
\hline Pharmacist & $3 / 58(5)$ & $3 / 80(4)$ & $3 / 125(2)$ & 0.78 & 0.27 & 0.40 \\
\hline \multicolumn{7}{|l|}{ Providing instructions at discharge } \\
\hline Physician & $14 / 57$ (25) & $8 / 80(10)$ & $17 / 125(14)$ & 0.02 & 0.07 & 0.40 \\
\hline Physician and Nurse & $14 / 57(25)$ & $30 / 80(38)$ & $39 / 125(31)$ & 0.11 & 0.41 & 0.30 \\
\hline Nurse & $25 / 57$ (44) & $37 / 80(46)$ & $60 / 125(48)$ & 0.82 & 0.62 & 0.80 \\
\hline Pharmacist & $4 / 57$ (7) & $1 / 80(1)$ & $0 / 125(0)$ & 0.06 & 0.003 & 0.26 \\
\hline
\end{tabular}

Results are tabulated only out of those surveys with answers for the particular question. Percentage results are listed in parentheses.

Response totals may not always total $100 \%$ due to some respondents entering an answer of "Other."

clarity regarding identification of healthcare provider responsibility for specific process steps. By far the least uniformity is in the acquisition and documentation of the preadmission medication list. There is variability in who is assigned to perform this task, but a substantial number of respondents indicated that their process involved a "shared" responsibility between physicians and nurses. It is unclear whether this phenomenon reflects the complexity of inpatient medication information management, or is simply an attempt to distribute the work among providers. Sharing the work between physicians and nurses may increase the overall likelihood for compliance and possibly improve the safety and accuracy of the process, especially if the physicians and nurses take the medication history 
in a redundant fashion and share their findings. Conversely, compliance may decrease if each provider merely expects the other to complete the process. Optimally, an interdisciplinary workflow for medication history taking would be in place, involving both physicians and nurses, with the availability of pharmacist consultation in complex cases. However, our survey data suggest this is infrequent; resident physicians appear to be the ones shouldering substantial responsibility for medication reconciliation in tertiary academic centers. Further research into the accuracy of medication reconciliation processes involving different strategies for medication information collection would be useful.

We documented several barriers to successful implementation of medication reconciliation. Phy-

TABLE 4

Survey Results - Barriers to Implementation

\begin{tabular}{llll}
\hline Barrier to Implementation & Yes & No & Unsure \\
\hline Patient not knowing meds & $87 \%$ & $2 \%$ & $0 \%$ \\
Process takes too long & $53 \%$ & $28 \%$ & $8 \%$ \\
Med list not available & $80 \%$ & $9 \%$ & $0 \%$ \\
Process not worth effort & $16 \%$ & $60 \%$ & $12 \%$ \\
Cumbersome hospital systems & $52 \%$ & $33 \%$ & $4 \%$ \\
Formulary differences & $59 \%$ & $24 \%$ & $5 \%$ \\
Language barriers & $31 \%$ & $53 \%$ & $4 \%$ \\
No access to outside records & $63 \%$ & $23 \%$ & $2 \%$ \\
Lack of job clarity in process & $38 \%$ & $48 \%$ & $3 \%$ \\
Availability of med list at discharge & $27 \%$ & $57 \%$ & $3 \%$ \\
\hline
\end{tabular}

Response totals may not always total $100 \%$ due to some answers being left blank. Percentages reported are of the total of 295 surveys. sicians cited a lack of medication knowledge on the part of the patient and unavailable prior medication lists as substantial barriers to success. Many medication reconciliation processes are limited by issues of poor health literacy or inadequate patient knowledge about medications. This lack of medication knowledge is especially problematic for patients new to a healthcare system. It will be important to implement processes that not only reconcile medications accurately, but also make medication information available for future care episodes.

Time required to complete the process was also important. Certain elements of the medication reconciliation process are "new work," and integrating the process into existing workflows is crucial. Given the significant time commitment required, the rare involvement of pharmacists at most institutions is striking. It appears that hospital pharmacists do not currently "own" any of the medication reconciliation process steps at most facilities, despite having formal training in medication history-taking. In the 2006 ASHP national hospital pharmacy survey, one-third of pharmacists stated that there were not enough pharmacy resources to meet medication reconciliation demands; only $19 \%$ of those surveyed stated pharmacists provided medication education at discharge to more than $25 \%$ of their patients. ${ }^{9}$

This report has several limitations. The survey used was not comprehensive, and only represents a convenience sample of hospitalists attending a national meeting. Nearly 300 physicians

TABLE 5

Subgroup Analysis of Barriers to Implementation by Process Type

\begin{tabular}{|c|c|c|c|c|c|c|}
\hline \multirow[b]{2}{*}{ Barriers (Selected Questions) } & \multirow[b]{2}{*}{ Paper Only [P] } & \multirow[b]{2}{*}{$\begin{array}{l}\text { Computer } \\
\text { Only }[\mathrm{C}]\end{array}$} & \multirow[b]{2}{*}{$\begin{array}{l}\text { Paper and } \\
\text { Computer [PC] }\end{array}$} & \multicolumn{3}{|c|}{$P$ values (2-tailed) } \\
\hline & & & & P vs. C & P vs. PC & C vs. PC \\
\hline \multicolumn{7}{|l|}{ Process takes too long } \\
\hline Yes & 77/134 (57) & 19/31 (61) & $55 / 91(60)$ & 0.69 & 0.65 & 0.92 \\
\hline No & 43/134 (32) & 11/31 (35) & 28/91 (31) & 0.75 & 0.87 & 0.68 \\
\hline Unsure & 14/134 (10) & 1/31 (3) & 8/91 (9) & 0.21 & 0.80 & 0.27 \\
\hline \multicolumn{7}{|l|}{ Process not worth effort } \\
\hline Yes & 24/133 (18) & $3 / 31(10)$ & 17/91 (19) & 0.28 & 0.85 & 0.25 \\
\hline No & 93/133 (70) & 22/31 (71) & $62 / 91(68)$ & 0.91 & 0.75 & 0.76 \\
\hline Unsure & 16/133 (12) & 6/31 (19) & 12/91 (13) & 0.30 & 0.82 & 0.41 \\
\hline \multicolumn{7}{|l|}{ Cumbersome hospital systems } \\
\hline Yes & 86/133 (65) & 16/31 (52) & $46 / 92(50)$ & 0.18 & 0.03 & 0.85 \\
\hline No & $42 / 133(32)$ & 13/31 (42) & $42 / 92(46)$ & 0.29 & 0.03 & 0.70 \\
\hline Unsure & $5 / 133(4)$ & $2 / 31(6)$ & 4/92 (4) & 0.62 & 0.82 & 0.64 \\
\hline
\end{tabular}

Results are tabulated only out of those surveys with answers for the particular question. Percentage results are listed in parentheses.

Response totals may not always total $100 \%$ due to rounding. 
TABLE 6

Subgroup Analysis of Barriers to Implementation by Hospital Type

\begin{tabular}{|c|c|c|c|c|c|c|}
\hline \multirow{2}{*}{$\begin{array}{l}\text { Barrier to Implementation } \\
\text { (Selected Questions) }\end{array}$} & \multirow{2}{*}{$\begin{array}{l}\text { Academic } \\
\text { Centers }[\mathrm{AC}]\end{array}$} & \multirow{2}{*}{$\begin{array}{l}\text { Community } \\
\text { Teaching } \\
\text { Hospitals [CT] }\end{array}$} & \multirow{2}{*}{$\begin{array}{l}\text { Non-Teaching } \\
\text { Hospitals [NT] }\end{array}$} & \multicolumn{3}{|c|}{$P$ values } \\
\hline & & & & AC vs. CT & AC vs. NT & CT vs. NT \\
\hline \multicolumn{7}{|l|}{ Process takes too long } \\
\hline Yes & $37 / 58(64)$ & 49/78 (63) & $70 / 124(56)$ & 0.90 & 0.31 & 0.37 \\
\hline No & $15 / 58(26)$ & $24 / 78(31)$ & 42/124 (34) & 0.53 & 0.28 & 0.66 \\
\hline Unsure & $6 / 58(10)$ & $5 / 78(6)$ & $12 / 124(10)$ & 0.39 & 0.88 & 0.32 \\
\hline \multicolumn{7}{|l|}{ Process not worth effort } \\
\hline Yes & $7 / 58(12)$ & $16 / 78(21)$ & 23/123 (19) & 0.17 & 0.24 & 0.73 \\
\hline No & $42 / 58(72)$ & $52 / 78(67)$ & $84 / 123(68)$ & 0.53 & 0.59 & 0.88 \\
\hline Unsure & 9/58 (16) & $10 / 78(12)$ & $16 / 123(13)$ & 0.50 & 0.59 & 0.84 \\
\hline \multicolumn{7}{|l|}{ Cumbersome hospital systems } \\
\hline Yes & $36 / 58(62)$ & $46 / 79(58)$ & $69 / 123(56)$ & 0.64 & 0.45 & 0.78 \\
\hline No & 19/58 (33) & $32 / 79(41)$ & 46/123 (37) & 0.34 & 0.60 & 0.57 \\
\hline Unsure & $3 / 58(5)$ & $1 / 79(1)$ & $8 / 123(7)$ & 0.16 & 0.61 & 0.049 \\
\hline \multicolumn{7}{|l|}{ Formulary differences } \\
\hline Yes & $37 / 58(64)$ & $61 / 78(78)$ & $74 / 123(60)$ & 0.07 & 0.61 & 0.009 \\
\hline No & $16 / 58(28)$ & 14/78 (18) & 41/123 (33) & 0.17 & 0.50 & 0.02 \\
\hline Unsure & $5 / 58(8)$ & 2/78 (3) & $8 / 123(7)$ & 0.19 & 0.81 & 0.22 \\
\hline \multicolumn{7}{|l|}{ Language barriers } \\
\hline Yes & 28/58 (48) & 28/77 (36) & $34 / 123(28)$ & 0.16 & 0.009 & 0.24 \\
\hline No & $28 / 58(48)$ & $46 / 77(60)$ & $82 / 123(67)$ & 0.17 & 0.016 & 0.32 \\
\hline Unsure & 2/58 (3) & $3 / 77(4)$ & 7/123 (5) & 0.76 & 0.54 & 0.74 \\
\hline \multicolumn{7}{|l|}{ No access to outside records } \\
\hline Yes & $38 / 58(66)$ & $60 / 79(76)$ & $87 / 123(71)$ & 0.20 & 0.50 & 0.44 \\
\hline No & $18 / 58(31)$ & $18 / 79(23)$ & $33 / 123(27)$ & 0.30 & 0.58 & 0.52 \\
\hline Unsure & $2 / 58(3)$ & $1 / 79(1)$ & $3 / 123(2)$ & 0.39 & 0.68 & 0.58 \\
\hline \multicolumn{7}{|l|}{ Lack of job clarity in process } \\
\hline Yes & $26 / 58(45)$ & $31 / 79(39)$ & 49/121 (40) & 0.48 & 0.53 & 0.89 \\
\hline No & $28 / 58(48)$ & $46 / 79(58)$ & $68 / 121(56)$ & 0.25 & 0.32 & 0.78 \\
\hline Unsure & $4 / 58(7)$ & 2/79 (3) & 4/121 (3) & 0.28 & 0.22 & 0.75 \\
\hline \multicolumn{7}{|c|}{ Availability of med list at discharge } \\
\hline Yes & 20/58 (34) & $24 / 79(30)$ & $35 / 120(29)$ & 0.62 & 0.50 & 0.88 \\
\hline No & $36 / 58(62)$ & $54 / 79(68)$ & $78 / 120(65)$ & 0.47 & 0.70 & 0.66 \\
\hline Unsure & $0 / 58(0)$ & $1 / 79(1)$ & $7 / 120(6)$ & 0.45 & 0.06 & 0.08 \\
\hline
\end{tabular}

Results are tabulated only out of those surveys with answers for the particular question. Percentage results are listed in parentheses.

Response totals may not always total $100 \%$ due to rounding.

responded, representing both teaching and private hospital settings. We consider the response rate of $37 \%$ reasonable for a survey of this nature, and the variety of processes described is likely indicative of the overall status of medication reconciliation implementation. The over-representation of certain institutions in our survey is possible, especially those with large or influential hospital medicine programs. Our survey did not ask respondents to name their home institutions. In addition, this design is open to a convenience sample bias, in that surveying only national meeting attendees (rather than the entire SHM membership) risks overinclusion of those hospitalists involved in leadership roles and quality improvement projects. Despite this, the variety of processes described is likely indicative of the overall status of medication reconciliation implementation in mid-2006. It is possible that processes have become more uniform nationwide in the interim.

Our survey results reflect the complexity surrounding medication reconciliation. It appears that full implementation has not yet occurred everywhere, significant barriers remain, and outcome measurement is limited. Importantly, physicians, nurses, and pharmacists do not have standardized roles. Responsibility for medication reconciliation has predominantly been added to the existing duties of inpatient physicians and nurses, with limited involvement of pharmacists. Hospitalists are well- 
positioned to lead the ongoing implementation of medication reconciliation processes and should take advantage of their systems knowledge to effectively partner with other physicians, nurses, and pharmacists to achieve success in medication reconciliation.

\section{ACKNOWLEDGMENTS}

The authors thank Ken Epstein, MD, and Renee Meadows, MD, along with the entire SHM Medication Reconciliation Task Force for their helpful review and comments on the article.

2006 SHM National Meeting Medication Reconciliation Survey Questions

\section{APPENDIX}

1. Which setting best describes your primary practice setting?

Academic, tertiary-care center

Non-academic community hospital

Other:

Community-based academic center

2. For which patient population do you provide care?
Adults only
Pediatrics only
Adults and pediatrics

3. Mark the single best statement that describes the current state of medication reconciliation implementation at your institution:

Fully implemented across all departments

Implemented in some hospital departments but not all

Still in planning stages of how to implement medication reconciliation

I am unaware of any plans to implement medication reconciliation

Have never heard of medication reconciliation

4. Were you or another hospitalist that you are aware of involved in the development or implementation of the medication reconciliation process at your organization?

Yes - played an active role (e.g. member of committee or task force charged with development and implementation)

Yes - played a peripheral role (reviewed process and implementation plan once developed)

No

5. Which process best describes your medication reconciliation process
Paper-based
Both paper- and computer-based components
Computer-based
Don't know

6. Are you measuring compliance with your process in any way?

$\begin{array}{lll}\text { Yes } & \text { No } & \text { Don't know } \\ \text { Yes } & \text { No } & \text { Don't know }\end{array}$

7. Are you measuring outcomes of your process in any way?

Yes

and patient safety?

8. How do you think your current medication reconciliation proces
No impact

Positive impact Don't know

9. Please mark the person(s) who are performing each of listed aspects of medication reconciliation:

$\mathrm{P}=$ physician; $\mathrm{N}=$ nurse; $\mathrm{Ph}=$ pharmacist.

9.1 Obtaining the current list of patient home medications

9.2 Documenting list of patient home medications

9.3 Reconciling home medications with currently ordered

9.4 Updating/documenting changes to patient's discharge

9.5

Providing medication instructions to the patient

Communicating medication changes to follow-up clinicians

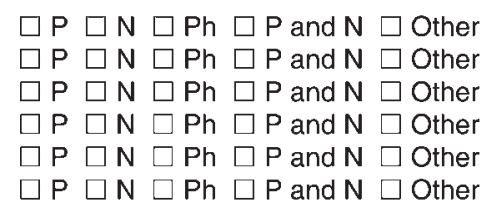

10. Please identify issues from the list below that are potential barriers in your current medication reconciliation process:
10.1 Patient does not know medications:
$\square$ Yes
$\square$ Yes Med recon process takes too long:
Medication list not available:
$\square$ Yes
$\square$ No
$\square$ No
$\square$ No
Med recon process not worth the effort:
$\square$ Yes
$\square$ Yes
$\square$ No
$\square$ No
Inpatientoutpatient formulary differences:
$\square$ Yes
$\square$ No
$\begin{array}{ll}10.7 & \text { Language barrier: } \\ 10.8 & \text { Difficulty getting outside records: }\end{array}$
$\square$ Yes
$\square$ Yes
$\square$ No
10.9 Lack of job clarity on who does med
$\square$ Yes
$\square$ No
$\square$ No
$\square$ Unsure
$\square$ Unsure
$\square$ Unsure
$\square$ Unsure
$\square$ Unsure
$\square$ Unsure
$\square$ Unsure
$\square$ Unsure
$\square$ Unsure
$\square$ Unsure
10.10 Availability of med list on discharge:
$\square$ Yes
$\square$ No 
Address for correspondence and reprint requests: Dr. Brian Clay, University of California San Diego, 200 West Arbor Drive, Mail Code 8485, San Diego, CA 92103. Telephone: 619-471-9194; Fax: 619-543-8255; E-mail: bclay@ucsd. edu

Received 5 November 2007; revision received 2 February 2008; accepted 14 March 2008.

\section{REFERENCES}

1. Kohn LT, Corrigan JM, Donaldson MS, eds. To Err Is Human: Building a Safer Health System. Washington, DC: National Academy Press; 1999.

2. Barnsteiner JH. Medication reconciliation: transfer of medication information across settings - keeping it free from error. Am J Nurs. 2005;105(3 Suppl):31-36.

3. Gleason KM, Groszek JM, Sullivan C, et al. Reconciliation of discrepancies in medication histories and admission orders of newly hospitalized patients. Am J Health-Syst Pharm. 2004;61(16):1689-1695.
4. Pronovost P, Weast B, Schwartz M, et al. Medication reconciliation: a practical tool to reduce the risk of medication errors. J Crit Care. 2003;18(4):201-205.

5. Paquette-Lamontagne N, McLean WM, Besse L, Cusson J. Evaluation of a new integrated discharge prescription form. Ann Pharmacother. 2001;35(7-8):953-958.

6. Rozich J, Howard RJ, Justeson JM, et al. Patient safety standardization as a mechanism to improve safety in health care. Jt Comm J Qual Saf. 2004;30(1):5-14.

7. Himmel W, Tabache M, Kochen MM. What happens to longterm medication when general practice patients are referred to hospital? Eur J Clin Pharmacol. 1996;50(4):253-257.

8. Varkey P, Reller MK, Smith A, et al. An experiential interdisciplinary quality improvement education initiative. Am J Med Qual. 2006;21(5):317-322.

9. Pedersen CA, Schneider PJ, Scheckelhoff DJ. ASHP national survey of pharmacy practice in hospital settings: monitoring and patient education-2006. Am J Health-Syst Pharm. 2007;64(5):507-520. 